\title{
Risky-Play at School. Facilitating Risk Perception and Competence in Young Children
}

\author{
Ann Lavrysen ${ }^{\mathrm{a}}$ Els Bertrands ${ }^{\mathrm{b}}$, Leene Leyssen ${ }^{\mathrm{b}}$, Lieve Smets ${ }^{\mathrm{b}}$, Anja \\ Vanderspikken $^{\mathrm{c}}, \&$ Peter De Graef ${ }^{\mathrm{d}, \mathrm{e}}$ \\ ${ }^{a}$ KU Leuven, Department of Kinesiology, Leuven, Belgium \\ ${ }^{b}$ UC Leuven-Limburg, Department of Teacher Education, Leuven, Belgium \\ ${ }^{c}$ UC Leuven-Limburg, Department of Business Studies, Leuven, Belgium \\ ${ }^{d}$ UC Thomas More Antwerpen, Department of Psychology, Antwerp, Belgium \\ ${ }^{e} K U$ Leuven, Department of Psychology, Leuven, Belgium
}

Corresponding author

Ann Lavrysen

KU Leuven - Department of Kinesiology

Movement Control and Neuroplasticity Research Group

Tervuursevest 101, box 1501

B-3001 Leuven (Belgium)

Phone: $\quad+32-16-37.95 .98$

Fax: $\quad+32-16-32.91 .97$

E-mail:ann.lavrysen@faber.kuleuven.be 


\section{Abstract}

Recent research indicates that risk competence and perception can be improved through the learning environment. The project 'Riscki' examined how risk perception and risk competence in young children between 3 and 8 years can be observed and measured within the classroom and school context. An intensive package of risky-play activities was administered over a 3-months period to two classes ( 4 and 6 year olds) and two age-matched classes served as controls.

Before and after the intervention period, quantitative and qualitative aspects of risk competence were evaluated in all children by 1) a change detection paradigm, 2) teacher ratings, and 3) independent observer's qualitative ratings. The results showed that risk perception and competence in young children can be improved through an intensive offer of risky-play activities at school. Moreover, the risk detection test and observational questionnaires are promising instruments to measure risk competence.

Keywords: early childhood; risky play; risk perception; risk competence; learning 


\section{Introduction}

Recent research focuses on the individual experience of risky play (Sandseter, 2010; Adams, 2001) and the impact of the learning environment (Ball, 2002; Stephenson, 2003). It has been suggested that a learning environment can make a difference and it is possible to measure a growth in risk competence and perception (Vetter, Kuhnen, \& Lensing-Conrady, 2008). Children's play and hence opportunities for risky-play occur at or around home, outdoors or in early childhood education and care settings. Each of these setting offer different opportunities and affordances for risky play (Kernan, 2014; Helen Little, Wyver, \& Gibson, 2011).

Children naturally seek to test their boundaries and engage in risk-taking play. The focus of risks in play is mainly on thrilling and exciting forms of play that involve an 'acceptable risk' of physical injury (Sandseter, 2009b). The risks should also imply a 'benefit' for the child and are being viewed as risky by the child (Little, Wyver, \& Gibson, 2011; Little \& Wyver, 2010). An example is climbing that is judged by the children as fun and exciting and where they know that they could fall or hurt themselves but accept this risk. According to Sandseter's (2007a, 2007b) observations in two Norwegian preschools, risky play can be categorized in six categories: play with great heights, play with high speed, play with harmful tools, play near dangerous elements, rough-and-tumble play and play where children can 'disappear'/get lost.

Overall, it is now well accepted that risky play is necessary for a child in order to develop risk-taking skills and learn how to cope with risky situations (Brussoni, Olsen, Pike, \& Sleet, 2012). This way, a child can obtain risk competence. Significant elements of risky play in children are: attempting something never done before; feeling on the borderline of 'out of control' often because of height or speed and overcoming fear (Stephenson, 2003). Depriving children from age-adequate risk play will hinder normal child development (Alexander, Frohlich, \& Fusco, 2012) and is being associated 
with the development of fear, discomfort and dislike of the environment (Sandseter \& Kennair, 2011).

Over the last decades there has been a large decline in outdoor play and thus also risky-play opportunities in children across Europe (Clements, 2004). Outdoor play opportunities are decreasing and many countries do not have a cultural heritage of spending time in nature as for example Nordic countries. Therefore, it is important to implement risky-play activities within the formal setting of preschool education to create opportunities to increase risk competence in very young children (Brussoni et al., 2014; Nikiforidou, Pange, \& Chadjipadelis, 2012).

Furthermore, concerns about safety have caused an increasing restriction in risky-play opportunities (Ball, 2002; Stephenson, 2003), but failed to prevent accidents. Moreover, the warning has been raised that overprotection of this young generation is a much bigger risk because it impacts negatively on their health and their ability to cope with the unpredictability of daily functioning (Gill, 2007; Little \& Wyver, 2008). New initiatives and movements take these concerns seriously by redesigning playgrounds into exciting and challenging experiment environments (Bundy et al., 2009) and by focusing on the utilization of affordances in an outdoor environment (Kernan, 2014; Helen Little et al., 2011). Johnson, Christie and Wardle (2005) have similar arguments to advocate for the importance of outdoor play in children, one of them is the development of risk-taking skills.

A definition of risk-taking skills brings us to the multidimensional concept of risk competence. In the context of the present study, risk competence is defined as the competence to see opportunities in a risky situation and consider either a) to engage in groundbreaking activities, or b) to transform it in a more manageable/controllable situation, or c) not to participate. This positive view is grounded on a realistic appraisal 
of one's own experiences and capacities on the one hand and a realistic estimate of the risks involved (i.e., risk perception) on the other (Vetter et al., 2008). Risk perception is defined as 'the subjective assessment of the probability of a specified type of accident happening and how concerned we are with the consequences. To perceive risk includes evaluations of the probability as well as the consequences of a negative outcome.' (Sjöberg, Moen, \& Rundmo, 2004, p8). In this way, risk perception focuses on the perception and appraisal of a situation before making a decision to act and is therefore part of risk competence.

Although research on the development of risk competence and risk perception in very young children is scarce, there is growing evidence that even preschool children are risk-seeking and to some degree risk competent (Little \& Wyver, 2010; Sandseter, 2007b, 2009c; Stephenson, 2003). Moreover and besides the more general health benefits, risky play has a positive impact on risk perception and competence skills (Christensen \& Mikkelsen, 2008). This study on 10-12 year old children describes a link between engagement in risky play and the ability to negotiate risk in relation to the children's individual capacities. Research implementing this in a (pre)school contex, however, is scarce. Apart from the influence of playground design and affordances (Barbour, 1999; Kernan, 2014; Sandseter, 2009a; Staempfli, 2008) there is also an important role for parents, ECE practitioners, and more general the school staff and management. Their beliefs and attitudes towards risk can stand as a barrier against risktaking behaviour. Conversely, a positive attitude would encourage children and improve their risk-taking skills (Brussoni et al., 2012; Little, 2010; Little et al., 2011; Sandseter, 2014).

An important study is the Bonner Risikostudie (Vetter, Kuhnen, \& LensingConrady, 2004; Vetter et al., 2008) on (progress in) risk competence in children 
following an intervention. In this project 416 children in 15 schools participated in a 3 year intervention study. Half of the children received an intense offer of psychomotor activities. Parents and teachers were asked to fill out a battery of questionnaires about accidents and the children's risk competence, which was seen as a multidimensional construct covering sensorimotor skills, self concept and social competences. The Bonner study presented promising results but failed to show significant differences in risk competence skills due to the intervention. As there was only one teacher per school responsible for both the control and intervention groups, it was suggested that there was a Hawthorne effect or in other words an impact of this teacher on the rest of the team and thus on the children of both groups.

The present experimental study was part of a larger multidisciplinary project 'Riscki' (see http://riscki.khleuven.be for more information and details regarding the procedure and instruments), covering educational, regulatory and insurance matters related to incorporating risky-play activities at school. The goal of this experimentally designed study was to improve risk competence within the reality of a class context in young children between 3 and 8 years old. A secondary goal was to develop and evaluate instruments for testing risk competence in young children. An intensive package of risky-play activities was administered over a 3-months period to two classes (4-6 year olds) and two classes served as controls. Before and after the intervention period, quantitative and qualitative aspects of risk competence were evaluated in all children by 1) a change detection paradigm, 2) teachers ratings and 3) independent observers qualitative ratings. In this way, objective measures were obtained from different perspectives, covering the child itself, their teachers working with them on a daily basis and independent observers. 


\section{Methods}

\section{Participants}

The school that participated in the project was located in a city of 90.000 inhabitants and in a sub municipality of about 22500 inhabitants. The school counted around 350 preschool pupils and around 650 children in elementary school, among which $12 \%$ with a lower SES. This percentage is representative for the neighborhood and a little lower than the average in Flanders. The class groups consisted of 20 to 23 pupils representing a normal class size in Flanders. All teachers involved in the project had a bachelor degree as teacher in preprimary or primary education and were very experienced. One of the 4 actively involved teachers was male. One teacher was minus 35 years old, the others $50+$. The school was located nearby a university college of teacher training which means that the school was strongly involved in preservice workplace training of student teachers and in practice-based research projects.

Two classes of preschool and two classes of primary school children (a total of 87 children) participated in the present study. Data of children that did not understand the task, had language problems or data of children that did not participate in both measurements were excluded, leaving a total sample of 76 participants. For each grade, one class served as the control group and received the normal curriculum $(\mathrm{N}=36,21$ boys and 15 girls $)$ and one class was the experimental group $(\mathrm{N}=40,18$ boys and 22 girls). They received an intervention specifically targeting risk competence. Children from the preschool group were $4.5+0.3$ years old and the primary school children were $6.6 \pm 0.5$ years old.

\section{Ethics}

This study was done in line with the KU Leuven Association policies on practice-based 
research. As young children were involved that were not able to give fully-informed consent, informed consent was obtained by proxy from parents. Parents and children were informed about the project and debriefed afterwards. Children were always invited to participate in the activities without ever forcing them. Care was taken to explain what they were going to do and what was going to happen. The children were made aware that they were free to let the researcher know if they did not want to participate at any moment. The teachers and assistants were also observant for non-verbal indications of withdrawing, such as frowns or turning away. As this was a longer-term study, the initial consent was reaffirmed on different occasions. All teachers that volunteered for the project were informed about the purpose of the project and there were frequent interactions between the teachers and researchers during the intense period of cooperation.

\section{Tasks}

Risk Perception Test. The task was set-up as a change-detection or Flicker paradigm (Rensink, O'Regan, \& Clark, 1997). In this paradigm pairs of images are alternated with a gray field briefly $(500 \mathrm{msec})$ presented in between the two images. Participants are quite insensitive to changes in the visual scene, a mechanism known as change blindness. However, when visual attention is allocated to specific regions in the scene, information is maintained across time and changes will be detected more rapidly. In the present experiment, the two alternating images differed in one or more aspects, which made the situation either more dangerous (risky change) or not (neutral change). Faster response times to risky than to neutral changes thus reveal attentional focus to risk in the scene and consequently, risk competence. To provide an age-fair assessment, the presentation time of the images was $500 \mathrm{msec}$ for the 6 year olds and $1000 \mathrm{msec}$ for the 4 year olds. Twenty different situations were used in the test, covering the six categories 
of risky play (Sandseter, 2007a). The task of the participant was to freely view the flickering display and hit the space bar when the change was detected. Children were asked to respond as fast as possible and to verbalize the change. The response was written down by the assistant and verified in order to reduce guessing, but also to check the accuracy of the response (\% correct responses). Because of the complexity of the actions a trained research assistant pressed the key for the 4-year-old children. The 6year-old children pressed the space bar themselves. Reaction time (RT) was the time between the start of the first image and pressing the space bar. Two versions of the test with 30 picture-pairs each were developed and randomized across children and test sessions, so that children did not get the same pictures in the pre and post session.

Bonner Questionnaire. The children were observed by their teachers using a translated version of the Bonner questionnaire that was previously used and validated in a similar intervention study (Vetter et al., 2004, 2008). The questionnaire consisted of 23 questions each rated on a five-point scale. A principal component analysis (cfr. Vetter et al., 2008) yielded five different factors of risk competence: social competence, self esteem, (low) conflict sensitivity, concentration and motor control.

Observations. The observational instrument was based on the process-oriented child monitoring system for young children (Laevers, 2001) and the items defined as important for risk competence in the Bonner study (Vetter et al., 2008) were selected: well-being, involvement, social competence, self management/self steering and motor competence. Risk competence was added as additional item of interest. The children participated in small groups (5-6 children) in a game where they could freely experiment with wheeled boards and rolling materials on slopes varying in steepness. These situations were filmed and evaluated offline by independent observers. The children were individually scored on a 5-point scale on the aforementioned items. 


\section{Procedure}

In order to evaluate the changes in risk competence, half of the children (i.e., two classes) underwent a 3-month training program with risky situations (experimental group). The other two classes participated in the standard educational activities (control group). The experimental groups received two different activities per week, thus they spent around 2 hours per week on risky activities. One activity was presented in the gym by the gym teacher once a week and a second classroom activity was done by their regular teacher and was repeated on several occasions during the week. The activities ranged over the six categories described by Sandseter (2007a), except for the category of presence of dangerous elements. The 3 months were subdivided by two short holiday breaks ( 3 weeks -1 week holiday -5 weeks -2 weeks holidays -6 weeks). Each child was tested for risk perception and competence one week before (pre test) and after (post test) this intervention period.

\section{Data Analysis}

Risk Perception Test. A few steps were taken to prepare the data of the change detection task for analysis. First, only correct answers to change-detection trials were regarded (3738 observations). Second, data of four children were left out: one of these children only performed the pre-test, the three others did not understand the task, had language difficulties or lost their attention very quickly. The pre and/or post test was ended prematurely in these three children because of these difficulties. Outliers (RT $>3$ SDs from the average per participant/moment/stimulus kind) were removed from the analysis. Specifically 32 outliers ( $0.85 \%$ of the data) were removed, leaving 3706 observations for the analysis. The dataset was aggregated per participant, test moment and stimulus kind. The reaction times were log-transformed and the proportion correct data were SQR-transformed to get a better fit to a normal distribution. Both for reaction 
time and proportion correct answers, the data were analyzed using a GLM repeated measures design with Test Moment (pre - post) and Stimulus (neutral - risky change) as within-subject variables and Group (control - experimental) and Age (4 - 6 year olds) as between-subject factors.

Bonner Questionnaire. For the observational questionnaires, the scores of all negative items in relation to risk competence were reversed. In this way, the resulting dimensions (components) in the questionnaire could be interpreted positively: the higher the score, the better the risk competence. Cronbach's alpha were calculated per observer and per test moment (Vetter et al., 2008). One item was removed from the analysis due to an obvious misinterpretation (or mistranslation) of this item. Cronbach's alpha were acceptable as a measure for internal consistency and reliability for all dimensions (>.60), except for sensorimotor motivation at the first observation. Five components were withheld: social competence, self esteem, (low) conflict sensitivity, concentration and motor control. For each component, a GLM repeated measures analysis was performed with Test Moment (pre - post) as repeated variable and Group (control - experimental) and Age (4 - 6 year olds) as between-subject factors.

Observations. All children participated in the observational situation. However, a video observation was done only on the five best and five weakest children of each group based on the scores of the risk perception (pre) test ${ }^{1}$. Two independent observers blind rated the children over the six items mentioned before. Observer 1 did 29 observations and observer 2 performed 28. Only these participants that received both pre and post scores were taken into account for this analysis $(\mathrm{N}=27)$. For each of the six items, a GLM repeated measures analysis was performed with Test Moment (pre - post) as repeated variable and Group (control - experimental) and Age (4 - 6 year olds) as between-subject factors. 
Cronbach's alpha were calculated per observer and aggregated over test moment (see Table 1). High correlations were found between risk competence and all other dimensions, in particular with self-management and self-steering, involvement and well-being. Risk competence was therefore a general factor encompassed within the other factors. These results confirm that children develop competent behaviour when they are feeling good and are involved in the play.

Table 1: Average correlations between the different scores for both observers

\begin{tabular}{|c|c|c|c|c|c|}
\hline & 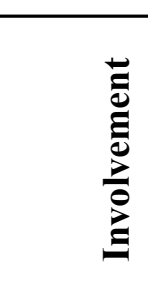 & 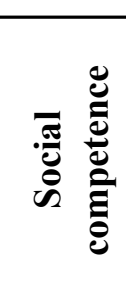 & 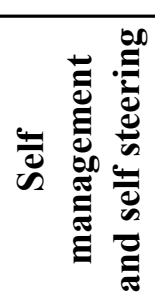 & 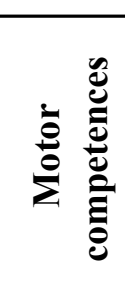 & 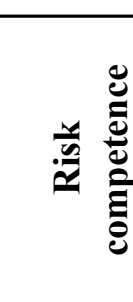 \\
\hline Well-being & $* * 0.685$ & $* 0.43$ & $* * 0.7$ & $* 0.47$ & $* * 0.53$ \\
\hline Involvement & & $* 0.425$ & $* * 0.625$ & $* 0.39$ & $* * 0.655$ \\
\hline Social competence & & & $* * 0.625$ & 0.20 & $* 0.47$ \\
\hline Self management and self steering & & & & $* * 0.54$ & $* * 0.69$ \\
\hline Motor competences & & & & & $* * 0.51$ \\
\hline
\end{tabular}

Correlations between Tests. The results and scores on the abovementioned tasks were aggregated and compared by Spearman correlations to find interplay between tests. More specifically, for the risk perception test, the variables RT and \% correct responses were averaged over test session (pre vs. post) and stimulus kind (neutral vs. risky). For the Bonner Questionnaire and the observations, one global measure was yielded per participant by averaging all components/items per test session (pre and post). 


\section{Results and Discussion}

\section{Risk Perception Test}

It was hypothesized that children participating in the risk competence intervention would show a larger decrease in reaction time for risky changes than children of the control group. No difference was expected between groups for neutral changes.

Reaction Time. The reported reaction times are backtransformed (EXP)

estimated marginal means and standard errors of means. For an overview of the results, see Figure 1. The analyses of reaction times revealed main effects for Test Moment $\left(F_{1,72}=229.21, p<.001\right)$, Age $\left(F_{1,72}=23.51, p<.001\right)$ and for Stimulus Kind $\left(F_{1,72}=\right.$ $45.71, \mathrm{p}<.001)$. During the pre test, children took on average $8848+1 \mathrm{~ms}$ to find the changes compared to $4647 \pm 1 \mathrm{~ms}$ at the post test. The 6 year olds responded overall faster $(5367 \pm 1 \mathrm{~ms})$ than 4 year olds $(7662 \pm 1 \mathrm{~ms})$. Furthermore, the main effect for Stimulus Kind revealed faster reaction times to risky $(5687 \pm 1 \mathrm{~ms})$ than to neutral changes $(7230+1 \mathrm{~ms})$. Apparently, the changes in these situations were overall easier to interpret or detect, or: all children demonstrated risk competence, by responding faster to the risky than to the neutral changes. The experimental group was overall faster at detecting changes $(5855+1 \mathrm{~ms})$ compared to the control group $(7030+1 \mathrm{~ms})$ as shown by a main effect for Group $\left(\mathrm{F}_{1,72}=6.22, \mathrm{p}<.05\right)$. Additionally, there was a significant interaction effect between Test Moment and Age $\left(\mathrm{F}_{1,72}=19.22, \mathrm{p}<.001\right)$, a three-way interaction between Test Moment, Group and Age $\left(\mathrm{F}_{1,72}=5.42, \mathrm{p}<.05\right)$ and also a 4-way interaction Test Moment x Stimulus Kind x Group x Age $\left(F_{1,72}=3.99, \mathrm{p}<.05\right)($ see

Figure 1). The 4 year olds in the experimental group showed a larger effect of the intervention, whereas this was not obvious in 6 year olds. In particular, the pre-to-post improvement for reaction time was larger for risky rather than for neutral changes. An explanation why the 6 year olds did not improve was perhaps that they were already fast 
in the pre test with not a lot of room for improvement. This might have been due to the test setup being too easy for 6 year olds in comparison to 4 year olds and their response times reaching a ceiling, or better a floor. Additionaly, assisting the younger children in pressing the response button might have contributed to this difference.
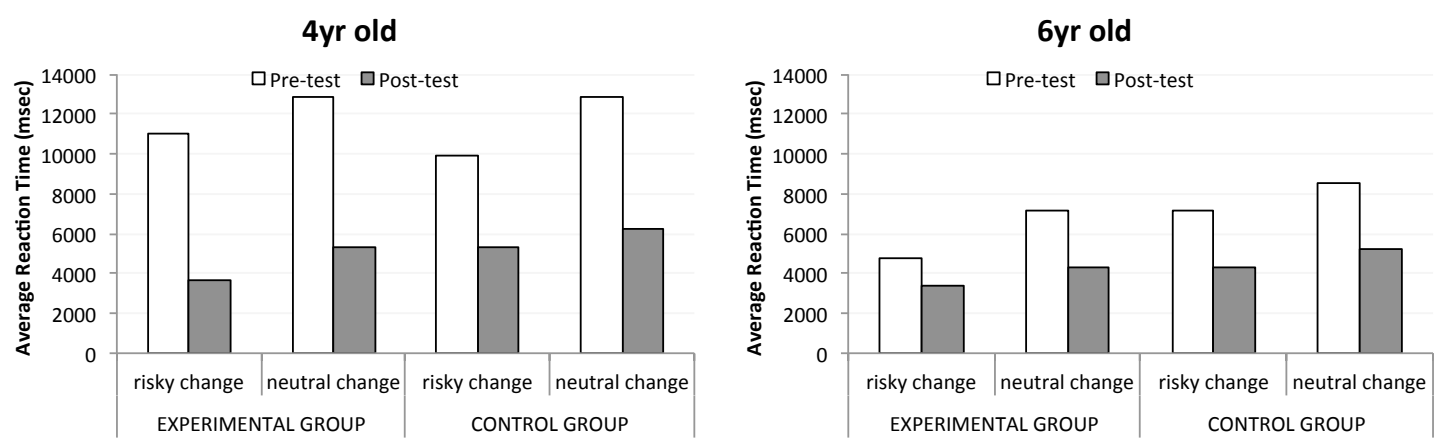

Figure 1: Average reaction time (ms) on the risk perception test per condition in 4-year olds (left) and 6-year olds (right)

Proportion of Correct Answers. The reported proportion of correct answers are back transformed (SQRT) estimated marginal means. For an overview of the results, see Error! Reference source not found.. Fewer risky $(77.2+12.2 \%)$ than neutral changes $(80.3+12.6 \%)$ were detected (main effect Stimulus Kind: $\left.F_{1,72}=9.67, p<.01\right)$. However, this effect was solely due to 6 year olds as demonstrated by an Age x Stimulus Kind interaction $\left(\mathrm{F}_{1,72}=16.45, \mathrm{p}<.001\right)$. Their proportion correct was $74.2+14.8 \%$ for neutral versus $81.4+15.1 \%$ for risky changes, while for the 4 year olds this was $80.1+14.1 \%$ for neutral versus $79.2+14.5 \%$ for risky changes. This might indicate that 6 year-olds were overall better at risk detection than 4 year olds. However, the proportion of correctly detected changes in 4 year olds was quite high and comparable to their older counterparts, as demonstrated by an absence of main or interaction effects involving Age. This might be because in some occasions the 6 year olds might have pressed the button impulsively before detecting the real change. The 4 year olds were assisted in responding and a response only occurred when the child verbalized a change. There was also a significant interaction Group $\mathrm{x}$ Test Moment $\left(\mathrm{F}_{1,72}=6.569, \mathrm{p}<.05\right)$. The 
experimental group improved from pre to post $(75.3+15.5 \%$ to $79+14.5 \%)$ whereas the control group did not show an improvement $(81.7+16$ to $78.9+14.8 \%)$.
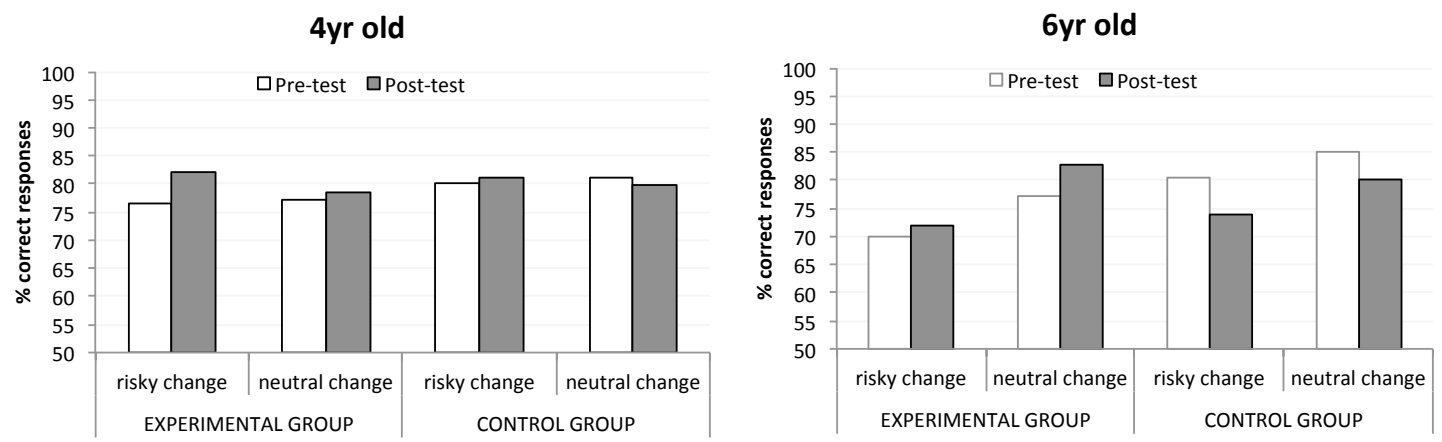

Figure 2: Percentage correct responses on the risk perception test per condition in 4year olds (left) and 6-year olds (right)

\section{Bonner Questionnaire}

The hypothesis here was that the teachers would rate the children, in particular in the experimental group, higher for each factor after the intervention due to their augmented skills and competences. An overview of the results is given in Table 2 and will be discussed separately per factor below.

Table 2: Average scores per factor for each of the experimental groups in the pre and the post session on the translated Bonner Questionnaire

\begin{tabular}{|c|c|c|c|c|c|c|c|}
\hline & & & 4 yea & & 6 yea & & \\
\hline & & & $\begin{array}{c}\text { Experimental } \\
\text { group }\end{array}$ & $\begin{array}{c}\text { Control } \\
\text { group }\end{array}$ & $\begin{array}{c}\text { Experimental } \\
\text { group }\end{array}$ & $\begin{array}{c}\text { Control } \\
\text { group }\end{array}$ & Total \\
\hline Social Competence & pre & $\mathbf{X}$ & 2.79 & 2.95 & 2.89 & 3.09 & 2.92 \\
\hline & & Stdev & 1.01 & 0.70 & 0.58 & 0.66 & 0.76 \\
\hline & post & $\mathbf{X}$ & 2.94 & 2.97 & 2.79 & 3.07 & 2.94 \\
\hline & & Stdev & 0.81 & 0.84 & 0.68 & 0.74 & 0.76 \\
\hline Self Esteem & pre & $\mathbf{X}$ & 2.94 & 3.00 & 2.94 & 3.43 & 3.06 \\
\hline & & Stdev & 0.84 & 0.76 & 0.56 & 0.56 & 0.72 \\
\hline & post & $\mathbf{X}$ & 3.17 & 3.11 & 3.35 & 3.07 & 3.18 \\
\hline & & Stdev & 0.82 & 0.64 & 0.57 & 0.55 & 0.66 \\
\hline (low) Conflict Sensitivity) & pre & $\mathbf{X}$ & 2.92 & 3.44 & 2.88 & 3.10 & 3.08 \\
\hline & & Stdev & 0.85 & 0.83 & 0.60 & 0.87 & 0.81 \\
\hline & post & $\mathbf{X}$ & 2.92 & 3.44 & 2.88 & 3.10 & 3.08 \\
\hline & & Stdev & 0.85 & 0.83 & 0.60 & 0.87 & 0.81 \\
\hline Concentration & pre & $\mathbf{X}$ & 2.61 & 2.87 & 2.86 & 3.12 & 2.85 \\
\hline & & Stdev & 1.06 & 0.74 & 0.73 & 0.55 & 0.81 \\
\hline & post & $\mathbf{X}$ & 2.75 & 2.75 & 3.16 & 3.25 & 2.97 \\
\hline & & Stdev & 0.99 & 0.95 & 0.60 & 0.55 & 0.82 \\
\hline Motor Control & pre & $\mathbf{X}$ & 3.27 & 3.39 & 2.80 & 3.31 & 3.19 \\
\hline & & Stdev & 0.61 & 0.46 & 0.45 & 0.63 & 0.58 \\
\hline & post & $\mathbf{X}$ & 3.46 & 3.56 & 2.99 & 3.35 & 3.34 \\
\hline & & Stdev & 0.49 & 0.40 & 0.43 & 0.52 & 0.50 \\
\hline
\end{tabular}


Social Competence. No significant results were found. The children were rated on average $2.93+0.76$ on a 5 -point-scale.

Self Esteem. There was a significant main effect for Test Moment $\left(\mathrm{F}_{1,79}=4.14\right.$, $\mathrm{p}<.05$ ). Self esteem was rated higher by the teachers during the second observation (post: $3.18 \pm 0.66$ versus pre: $3.06 \pm 0.72$ ). A significant interaction effect between Test Moment and Group $\left(\mathrm{F}_{1,79}=19.88, \mathrm{p}<.001\right)$ revealed that this was in particular the case for the experimental group. And finally a three-way interaction between Test Moment, Group and Age $\left(\mathrm{F}_{1,79}=10.51, \mathrm{p}<.05\right)$ showed that this progress and better rating for the experimental group was more prominent in the 6 year olds than in 4 year olds (Error! Reference source not found. left panel). This could be interpreted as a more positive evaluation by the teachers perhaps because of a better atmosphere in the groups with the increased offer.

(Low) Conflict Sensitivity. Similar to self-esteem, a main effect for Test Moment $\left(\mathrm{F}_{1,79}=7.93, \mathrm{p}<.01\right)$ was found and interaction effects between Test Moment $\mathrm{x}$ Group $\left(\mathrm{F}_{1,79}=8.26, \mathrm{p}<.01\right)$ and Test Moment $x$ Group x Age $\left(\mathrm{F}_{1,79}=5.97, \mathrm{p}<.05\right)$. The decrease in conflict sensitivity from pre to post test was also here more evident in the experimental group and more so for 6 than 4 year olds (Error! Reference source not found. middle panel).

Concentration. The factor concentration revealed main effects for Age $\left(\mathrm{F}_{1,79}=\right.$ 4.31, $\mathrm{p}<.05)$ and for Test Moment $\left(\mathrm{F}_{1,79}=4.47, \mathrm{p}<.05\right)$. As could be expected, 4 year olds got a lower score for concentration than 6 year olds and concentration was better at the second compared to the first observation for all children. An interaction effect between Test Moment and Group $\left(\mathrm{F}_{1,79}=4.23, \mathrm{p}<.05\right)$ revealed that the increase in 
concentration after the intervention period was greater in the experimental than in the control groups (Error! Reference source not found. right panel).

Motor Control. Motor control was rated higher in 4 year olds than in 6 year olds (main effect of Age $\mathrm{F}_{1,79}=8.93, \mathrm{p}<.01$ ). It should be noted that the rating was done relative to the age norm. These results thus do not necessarily mean a better motor control in the younger children. A main effect of Test Moment $\left(\mathrm{F}_{1,79}=14.26, \mathrm{p}<.001\right)$ revealed that there was indeed a progression from pre to post test. The control group scored higher than the experimental group (main effect of Group $F_{1,79}=6.89, p=.01$ ). As there were no interaction effects and we used existing class groups, a possible explanation here is the control groups were overall better.
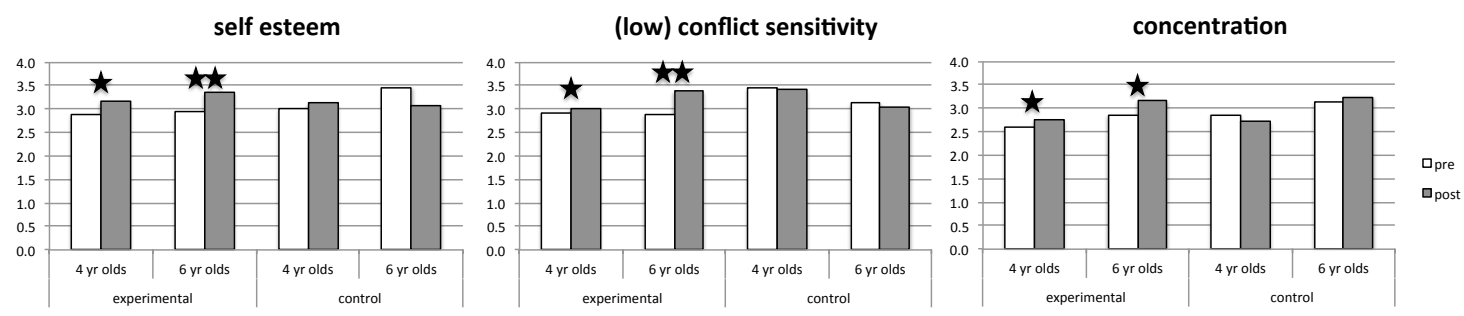

Figure 3: Average teacher ratings $\left({ }^{*} \mathrm{p}<0.05 ;{ }^{*} \mathrm{p}<0.01\right)$ for the items self-esteem, (low) conflict sensitivity and concentration

\section{Observations}

The children participated in small group play activities in order to observe their individual risk competence skills. It was hypothesized that the observation scores at post assessment would be higher, in particular for the children in the experimental groups.

Contrary to our expectations, the analyses of the observer ratings revealed no significant effects. Although there was a tendency towards improved risk competence, even the main effect of Test Moment failed to reach significance $\left(\mathrm{F}_{1,26}=3.18, \mathrm{p}=0.086\right)$. It should be kept in mind that, although all children participated in the observation game, only a limited number of observations $(\mathrm{N}=27)$ were done in the present experiment. 


\section{Correlations between Tests}

To test for coherence between the responses of teachers, children and independent observers, the results from the risk perception test, the Bonner questionnaire and the observations were correlated. As all tests were addressing at least some aspects of risk competence, we hypothesized to find correlations within, but also between tests.

Table 3: Matrix with correlation between all different tests and scores. Note that the significance level is lower for the correlations involving observers, as a smaller number of children were evaluated here.

\begin{tabular}{|c|c|c|c|c|c|c|c|c|c|c|c|c|}
\hline & \multicolumn{4}{|c|}{$\mathrm{RT}$ risk perception test } & \multicolumn{4}{|c|}{ \% correct risk perception test } & \multicolumn{2}{|c|}{ Teachers } & \multicolumn{2}{|c|}{ Observers } \\
\hline & pre risk & pre neut & post risk & post neut & pre risk & pre neut & post risk & post neut & pre & post & pre & post \\
\hline & 1 & 2 & 3 & 4 & 5 & 6 & 7 & 8 & 9 & 10 & 11 & 12 \\
\hline 1 & & $0.658^{* *}$ & $0.398^{* *}$ & $0.472^{* *}$ & $0.228^{* *}$ & 0.051 & 0.074 & $-0.322^{* *}$ & -0.117 & -0.115 & -0.278 & -0.246 \\
\hline 2 & & & $0.372^{* *}$ & $0.527^{* *}$ & 0.040 & -0.198 & $0.053^{\prime}$ & $-0.272^{*}$ & $-0.180^{\prime}$ & $-0.225 *$ & $-0.504 * *$ & $-0.441^{*}$ \\
\hline 3 & & & & $0.654^{* *}$ & 0.031 & 0.033 & $-0.181^{\prime}$ & $-0.228 *$ & -0.009 & -0.134 & -0.289 & -0.138 \\
\hline 4 & & & & & 0.008 & 0.030 & $-0.061^{\prime}$ & $-0.319 * *$ & -0.163 & -0.217 & -0.306 & -0.229 \\
\hline $\mathbf{5}$ & & & & & & $0.445^{* *}$ & 0.180 & 0.206 & $0.372^{* *}$ & $0.301 * *$ & 0.296 & 0.221 \\
\hline 6 & & & & & & & 0.188 & $0.325 * *$ & $0.416^{* *}$ & $0.39 * *$ & $0.498^{* *}$ & 0.289 \\
\hline 7 & & & & & & & & $0.31 * *$ & $0.132^{\mathrm{F}}$ & 0.183 & $0.365^{*}$ & 0.316 \\
\hline 8 & & & & & & & & & $0.322^{* *}$ & $0.401^{* *}$ & $0.433^{*}$ & 0.309 \\
\hline 9 & & & & & & & & & & $0.868^{* *}$ & $0.481^{* *}$ & $0.48^{* *}$ \\
\hline 10 & & & & & & & & & & & $0.457 * *$ & $0.366^{*}$ \\
\hline 11 & & & & & & & & & & & & $0.697^{* *}$ \\
\hline 12 & & & & & & & & & & & & \\
\hline
\end{tabular}

First of all, the correlation matrix revealed significant relations between all variables belonging to the same tests (

Table 3 diagonal). Only the percentage correct scores on the pre test for risk perception did not correlate with the post test results. As risk perception improved differently for the children in the experimental than control group, the post test score for the risky, but not for the neutral changes was not predictable from the pre test result. This indicates that our test was indeed sensitive enough to detect differences between responses to risky and to neutral changes and, thus, to detect progress in risk perception. There were also internal correlations for RT on the risk perception test. Probably, speed was a strategy and therefore less variation occurred within participants across sessions and stimuli. Overall, the results and scores from the pre test were often correlated with 
the same measures from the post test, indicating a high internal reliability for all tests used. The RT from the risk perception test correlated negatively with the $\%$ correct scores in the neutral situations. This means that faster responses coincided with a drop in performance. This effect also showed in the correlation between RT pre (neutral) with the scores of teachers and observers. This means that the faster children were rated lower behaviourally by both teachers and observers. And finally, there were high correlations between teacher and observer scores. This means both teachers and independent observers had a similar perception of the children's abilities.

Some variables correlated with (at least one measure from) each of the other tests. These were RT in the pre test on the neutral changes; \% correct on the post test for the neutral items; the teacher observation scores from the post test; and the observers' scores from the pre test. These results show that the scores and measures from the different tests were at least in some way related. That means that results from the assessment from the child's perspective, the teachers and independent observers are comparable and able to detect high and low performances and skills among children. Finally, and most importantly, these results support the use of the risk perception test as a promising tool for evaluating risk competence and risk competence and perception can be observed by both teachers and trained observers.

\section{General Discussion}

It has been suggested that risk competence can be improved through an intensive offer of risky play and activities within the preschool education context (Nikiforidou et al., 2012). In the present study, two classes of 4 and 6-year-old children received an intensive package of risky-play situations and two age-matched classes served as controls. A 3-month training programme resulted in improvements in risk perception and competence skills evaluated using a risk perception test, teachers' and independent 
observers' scores. Therefore, the results support that a short-term intervention in the school and classroom context can enhance risk competence skills in very young children. Additionally, easy-to-use and practical tests and observation protocols for risk competence were developed and evaluated.

The benefits of a multiweek intervention on risk competence were evident in both the risk perception test and the Bonner questionnaire results. The change-detection paradigm has been proven to be successful in school age children before (Shore, Burack, Miller, Joseph, \& Enns, 2006), but to our knowledge, this was the first time this paradigm was tested on children as young as preschool age. The risk perception test revealed a larger pre-to-post improvement for both experimental groups compared to the control groups, although the improvements were more evident in the 4 year old groups than in the six year olds. This does not necessarily mean that the younger participants improved more. The explanation can possibly be found in the fact that the test protocol was more sensitive for the younger children. In other words, the test was perhaps too easy for the older children, such that ceiling effects might have prevented the effects to show. Additionally, the test leader pressing the response button for the younger children might also explain part of the results. Therefore, the risk perception test requires further validation and adjustments. For example, the test parameters (e.g., stimulus presentation time), the quality of the pictures needs refinement and adaptations to different age groups should be made. Nevertheless, the test is a promising tool to study risk competence in very young children and will be applicable in a broad range of domains, for example hazard perception in traffic or play grounds.

The results of the Bonner questionnaires revealed that teachers report an improvement on risk competence due to the intervention in different areas, such as concentration, conflict sensitivity and self esteem. The children in the experimental 
groups of both ages improved more than the children in the control groups. Vetter and colleagues (2008) also demonstrated progress in risk competence but failed to reveal differences between control and experimental groups. Compared to their study, different class groups and teachers for the experimental and the control conditions reducing the impact of crosstalk between teachers and peers. For the factors self-esteem and (low) conflict sensitivity, the progress after the intervention was greater in the 6 year olds than 4 year olds. These results showed that the teachers reported more progress in the children that received the additional play activities. Whether these results were due to the impact of the intervention per se or more so due to a (more or less) subjective appraisal of the teachers of a better classroom atmosphere remains unclear. As these measures were related to other tests, the plausibility for the first interpretation is more likely. Whatever the case may be, the results on the Bonner questionnaire are interesting from an educational point of view, as it shows that teachers can make a difference through an offer of adventurous activities (Bundy et al., 2009; Sandseter, 2012, 2014; Vetter et al., 2008). Moreover, by broadening the activities, the teacher gets to see other competences in children and the teacher-child relationship is influenced in a positive way.

The rating of the children in the group play activities by independent observers failed to yield significant results. It should be noted that the time-consuming nature of this observation protocol was perhaps a limiting factor in these data. Only 27 of the 87 children were rated. Moreover, the observations take experience and probably the quality of the rating could be higher when given more time. Therefore, care should be taken when using observer ratings to detect progress in the school context. Although observations are a principal and helpful tool for teachers in detecting differences between children in a classroom context, the use of this instrument to evaluate progress 
after a short-term intervention seems to be limited and more time is needed for validation. The observational instrument in our study did show that a global assessment of risk competence is possible with good education and coaching of the teachers involved. This means that when teachers are coached, they are able to detect risk competence in play and adequately accompany the children on the playground (Vetter et al., 2008). One of the prerequisites here is acknowledging and conquering ones own fears and projections in order to promote and help develop risk competence in young children (Little et al., 2011; Sandseter, 2014).

Finally, the results and scores from different (sub)tests were correlated. It should be acknowledged that the risk perception test only focuses on the perceptual aspect of risk competence, whereas the observations and questionnaires focus on the more general concept of risk competence. The significant correlations confirmed that there was indeed interdependence between the developed instruments to evaluate risk competence. The lack of some correlations also implies that probably risk competence does not develop in the same way and speed in every child (Nikiforidou et al., 2012). This issue deserves further investigation.

As this study has applications to ECEC policy and practice, specific actions have been taken to disseminate and share our results. Part of the results were presented at the EECERA conference 2014 in Greece and published in ECEC journals (Bertrands et al., 2014; Leyssen, Smets, Vanderspikken, \& Bertrands, 2013). The website (http://riscki.khleuven.be; partially in English) makes the developed material available for schools, teachers and the community. The ideas were disseminated in different inservice courses in Flanders.

In conclusion, the results of the present small-scale study are promising as even in 4-year-old children risk perception and competence can be improved and measured in 
a simple way within the classroom and school context. Risk competence and improvements can be detected by a risk perception test, teacher ratings or independent observers. This research provides perspectives and calls for larger-scale interventions and initiatives promoting a balanced and healthy development of risk competence from as early as preschool age. 


\section{Footnotes}

${ }^{1}$ All children participated in small group ( 5 children) activities where different skills and behaviours needed to be observed. Video observation is a time-consuming procedure as for each of the participating children the situation needed to be evaluated several times. As the objective of the present study was to observe differences between children of varying skill level, a group of 5 best and 5 worst performing children on the risk perception pre test were selected a priori. 
This project was funded as practice-based scientific research project (PWO) by the UC Leuven-Limburg. The authors would like to thank the primary and pre-primary schools involved, in particular the staff, teachers and children from the H. Hartinstituut Heverlee; The students and collaborators from UC Limburg-Leuven, KU Leuven and UC Thomas More Antwerp that were involved in this project; and the collaborators from the Flemish Institute of Health Promotion and Prevention of Illness (VIGEZ), Belgium. 


\section{References}

Adams, J. (2001). Risk. London: Routledge.

Alexander, S. A., Frohlich, K. L., \& Fusco, C. (2012). Playing for health? Revisiting health promotion to examine the emerging public health position on children's play. Health Promotion International, 29, 155-164. doi:10.1093/heapro/das042

Ball, D. J. (2002). Playgrounds - risks, benefits and choices. London.

Barbour, A. C. (1999). The impact of playground design on the play behaviors of children with differing levels of physical competence. Early Childhood Research Quarterly, 14, 75-98. doi:10.1016/S0885-2006(99)80007-6

Bertrands, E., Leyssen, L., Smets, L., Vanderspikken, A., De Graef, P., \& Lavrysen, A. (2014). "Riscki ": Het stimuleren van risicocompetentie bij jonge kinderen. Tijdschrift Voor Jeugdgezondheidszorg, 36(5), 111-115.

Brussoni, M., Brunelle, S., Pike, I., Sandseter, E. B. H., Herrington, S., Turner, H., ... Ball, D. J. (2014). Can child injury prevention include healthy risk promotion? Injury Prevention, 1-4. doi:10.1136/injuryprev-2014-041241

Brussoni, M., Olsen, L. L., Pike, I., \& Sleet, D. A. (2012). Risky play and children's safety: Balancing priorities for optimal child development. International Journal of Environmental Research and Public Health. doi:10.3390/ijerph9093134

Bundy, A. C., Luckett, T., Tranter, P. J., Naughton, G. a., Wyver, S. R., Ragen, J., \& Spies, G. (2009). The risk is that there is "no risk": a simple, innovative intervention to increase children's activity levels. International Journal of Early Years Education, 17(1), 33-45. doi:10.1080/09669760802699878

Christensen, P., \& Mikkelsen, M. R. (2008). Jumping off and being careful: children's strategies of risk management in everyday life. Sociology of Health \& Illness, 30(1), 112-30. doi:10.1111/j.1467-9566.2007.01046.x

Clements, R. (2004). An investigation of the state of outdoor play. Contemporary Issues in Early Childhood, 5, 68-80. doi:10.2304/ciec.2004.5.1.10

Gill, T. (2007). No fear: Growing up in a risk averse society. London: Calouste Gulbenkian Foundation.

Johnson, J. E., Christie, J. F., \& Wardle, F. (2005). Play, development, and early education. Pearson: Allyn and Bacon. Retrieved from

http://books.google.be/books/about/Play_development_and_early_education.html? $\mathrm{id}=$ RhhKAAAAYAAJ\&pgis $=1$

Kernan, M. (2014). Opportunities and affordances in outdoor play. In L. Brooker, M. Blaise, \& S. Edwards (Eds.), The SAGE handbook of play and learning in early childhood (pp. 391-402). Los Angeles: SAGE. 
Laevers, F. (2001). Procesgericht kindvolgsysteem voor kleuters. Toelichting bij de competenties. Leuven: CEGO Publishers.

Leyssen, L., Smets, L., Vanderspikken, A., \& Bertrands, E. (2013). "Dat is kicken, man": Kinderen leren omgaan met risico, 29(3), 2-6.

Little, H. (2010). Relationship between parents' beliefs and their responses to children's risk-taking behaviour during outdoor play. Journal of Early Childhood Research. doi:10.1177/1476718X10368587

Little, H., \& Wyver, S. (2008). Outdoor play: Does avoiding the risks reduce the benefits? Australian Journal of Early Childhood, 33, 33-40.

Little, H., \& Wyver, S. (2010). Individual differences in children's risk perception and appraisals in outdoor play environments. International Journal of Early Years Education . doi:10.1080/09669760.2010.531600

Little, H., Wyver, S., \& Gibson, F. (2011). The influence of play context and adult attitudes on young children's physical risk-taking during outdoor play. European Early Childhood Education Research Journal, 19, 113-131. doi:10.1080/1350293X.2011.548959

Nikiforidou, Z., Pange, J., \& Chadjipadelis, T. (2012). Risk literacy in early childhood education under a lifelong perspective. Procedia - Social and Behavioral Sciences. doi:10.1016/j.sbspro.2012.06.343

Rensink, R. A., O’Regan, J. K., \& Clark, J. J. (1997). To see or not to see: The need for attention to perceive changes in scenes. Psychological Science, 8, 368-373. doi:10.1111/j.1467-9280.1997.tb00427.x

Sandseter, E. B. H. (2007a). Categorising risky play—how can we identify risk-taking in children's play? European Early Childhood Education Research Journal, 15, 237-252. doi:10.1080/13502930701321733

Sandseter, E. B. H. (2007b). Risky play among four and five year-old children in preschool. In Vision into Practice. Making Quality a Reality in the Lives of Young Children (pp. 248-257).

Sandseter, E. B. H. (2009a). Affordances for risky play in preschool: The importance of features in the play environment. Early Childhood Education Journal, 36, 439446. doi:10.1007/s10643-009-0307-2

Sandseter, E. B. H. (2009b). Characteristics of risky play. Journal of Adventure Education \& Outdoor Learning. doi:10.1080/14729670802702762

Sandseter, E. B. H. (2009c). Risky play and risk management in Norwegian preschools - A qualitative observational study. Safety Science Monitor, (1), 1-12. 
Sandseter, E. B. H. (2010). "it tickles in my tummy!”: understanding children's risktaking in play through reversal theory. Journal of Early Childhood Research. doi:10.1177/1476718X09345393

Sandseter, E. B. H. (2012). Restrictive safety or unsafe freedom? Norwegian ECEC practitioners' perceptions and practices concerning children's risky play. Child Care in Practice, 18, 83-101. doi:10.1080/13575279.2011.621889

Sandseter, E. B. H. (2014). Early childhood education and care practitioners' perceptions of children's risky play; examining the influence of personality and gender. Early Child Development \& Care, 184, 434-449. doi:10.1080/03004430.2013.794797

Sandseter, E. B. H., \& Kennair, L. (2011). Children's risky play from an evolutionary perspective: The anti-phobic effects of thrilling experiences. Evolutionary Psychology, 9, 257-284. Retrieved from http://www.ncbi.nlm.nih.gov/pubmed/22947972

Shore, D. I., Burack, J. A., Miller, D., Joseph, S., \& Enns, J. T. (2006). The development of change detection. Developmental Science. doi:10.1111/j.14677687.2006.00516.x

Sjöberg, L., Moen, B.-E., \& Rundmo, T. (2004). Explaining risk perception. An evaluation of the psychometric paradigm in risk perception research. Rotunde Publikasjoner Rotunde, 84, 1-33. Retrieved from $\mathrm{http}: / /$ scholar.google.com/scholar?hl=en\&btnG $=$ Search $\& \mathrm{q}=$ intitle:Explaining + risk + perception. + An + evaluation + of + the + psychometric + paradigm + in + risk + perception + research\#0

Staempfli, M. B. (2008). Reintroducing adventure into children's outdoor play environments. Environment and Behavior. doi:10.1177/0013916508315000

Stephenson, A. (2003). Physical risk-taking: Dangerous or endangered? Early Years, 23, 35-43. doi:10.1080/0957514032000045573

Vetter, M., Kuhnen, U., \& Lensing-Conrady, R. (2004). “Bonner Risikostudie”: Können gezielte Bewegungsangebote Riskiokompetenzen Stärken und Unfalle vermeiden? Bonn.

Vetter, M., Kuhnen, U., \& Lensing-Conrady, R. (2008). RisKids. Wie Psychomotorik hilft, Risiken zu meistern. Dortmund: Borgmann. 